\title{
Showrooming: The Effect of Gender
}

\author{
David J. Burns, dburns21@kennesaw.edu* \\ Pola B. Gupta, pola.gupta@wright.edu \\ Jennifer Hutchins, jhutch35@kennesaw.edu
}

\begin{abstract}
Retailing is in the midst of a significant structural change as the percentage of retail sales online is continuing to grow at the expense of retail sales in bricks-and-mortar outlets. One of the resulting complexities is the facilitation of showrooming, or consumers viewing, gathering information, and, at times, trying products at brick-and-mortar retail stores without purchasing there, then purchasing the products online from a different retailer often at a lower price. Although showrooming appears to be a popular and growing approach to shopping, interestingly, the activity has received relatively little empirical research attention. The objective of this study was to examine showrooming from a perspective of gender. Specifically, does consumers' gender affect how they view showrooming? The focus of this study was to examine the effect of an individual's gender on their shopping orientations, their propensities to engage in showrooming activity, the perceived ethicality of engaging in showrooming activity, and the importance of the benefits of buying in a physical store.
\end{abstract}

The following hypotheses were tested.

H1a: There exist no relationships between gender and the degree to which an individual is a deal shopper.

$\mathrm{H} 1 \mathrm{~b}$ : There exist no relationships between gender and the degree to which an individual is brand conscious.

H1c: There exist no relationships between gender and the degree to which an individual values customer service.

H1d: There exist no relationships between gender and the degree to which an individual views businesses as providing low quality products.

H2a: Male individuals are more likely to engage in showrooming activity than are female individuals.

H2b: Male individuals are more likely to view showrooming activity as ethical than are female individuals.

H2c: Male individuals are less likely to view the benefits of buying in a physical store as important than female individuals.

The sample was comprised of 405 students attending several marketing classes at a university located in the Midwest.

As expected, no differences were noted between males and females in any of the shopping orientations. This suggests that there is no basis to for retailers to treat individuals of different genders differently as it relates to the shopping orientations. The results, however, suggest that although the showrooming activity of male and female individuals may not have been observed to differ, males appear to be less troubled by the activity and females may view the benefits of buying at retail stores as more important than males. This suggests that gender affects individuals' reactions to conditions that may affect showrooming activity.

In conclusion, the results suggest that showrooming is not just a male or a female phenomenon among young adults. The results suggest that showrooming activity is a popular activity that is not limited to a single group or shopping orientation, raising serious questions for bricks-and-mortar retailers.

Keywords: showrooming, retailing, bricks-and-mortar, online retailing

Relevance to Marketing Educators, Researchers and Practitioners: Showrooming poses a potential threat to bricks-and-mortar retailers since it involves bricks-and-mortar retailers subsidizing their online competition.

Author Information:

David J. Burns is Chair and Professor of Marketing and Professional Sales in the Michael J. Coles College of Business at Kennesaw State University. 
Pola B. Gupta is a Professor of Marketing in the Raj Soin College of Business at Wright State University.

Jennifer Hutchins is an Assistant Professor of Marketing in the Michael J. Coles College of Business at Kennesaw State University.

\section{TRACK: Retailing}

